$\mathrm{DC}$ 스퍼터법과 비대칭 바이폴라 펄스 $\mathrm{DC}$ 스퍼터법으로 증착된 TiAIN 코팅막의 물성 비교연구

\author{
전성용*, 이태양 \\ 목포대학교 신소재공학과
}

\title{
A Comparative Study of TiAIN Coatings Deposited by DC and Pulsed DC Asymmetric Bipolar Magnetron Sputtering
}

\author{
Sung-Yong Chun*, Tae Yang Lee \\ Department of Advanced Materials Science and Engineering, Mokpo National University, \\ Jeonnam, 534-729, Korea
}

(Received August 1, 2014 ; revised August 20, 2014 ; accepted August 25, 2014)

\begin{abstract}
The paper presents the comparative results of TiAIN coatings deposited by DC and pulsed DC asymmetric bipolar magnetron sputtering systems. The results show that, with the decreasing duty cycle and increasing pulse frequency, the coating morphology changes from a columnar to a dense structure, with finer grains. Pulsed sputtered TiAlN coatings showed higher hardness, higher residual stress, and smaller grain sizes than dc prepared TiAIN coatings. Moreover residual stress of pulsed sputtered TiAIN coatings increased on increasing pulse frequency. Meanwhile, the surface roughness decreased continuously with increasing pulsed DC frequency up to $50 \mathrm{kHz}$.
\end{abstract}

Key words: Pulsed DC Sputtering, TiAIN, Asymmetric Bipolar, Duty cycle, Pulse frequency

\section{1. 서 론}

TiAlN은 고온에서도 내산화, 내마모, 내충격 등의 기계적 성질이 뛰어날 뿐만 아니라 고속작업에 적 합하다는 장점 때문에 절삭공구, 기계부품의 성능 과 수명을 향상시키기 위한 코팅막으로 많이 이용 되고 있다 ${ }^{1-2)}$. 그밖에 최근 화학, 광학용 반사경, 의 학 진단용 바이오 센서, 자외선 차단 고분자 표면 처리, 수처리, 수소 연료 전지의 촉매 지지 등으로 응용이 다양화 되고 있다-7). TiAIN 코팅막을 제작 하는 대표적인 방법으로 이온 플레이팅, 이온빔 스 퍼터법과 반응성 마그네트론 스퍼터법 등을 들 수 있다 ${ }^{8)} . \mathrm{PVD}$ 법 중에서도 마그네트론 스퍼터법은 뛰 어난 재현성과 밀착력 뿐만 아니라 높은 증착율과

*Corresponding author. E-mail : sychun@mokpo.ac.kr
낮은 기판온도에서도 코팅이 가능하기 때문에 가장 널리 사용되고 있다. 그러나 미세구조가 불균일한 주상구조를 나타내거나 다공성의 코팅막이 생성되 기 쉽기 때문에 물성 면에서는 불리하다 ${ }^{9)}$. 따라서 본 연구에서는 펄스 플라즈마의 중요 변수인 타겟 에 인가되는 듀티 싸이클과 펄스 주파수 인가방법 을 조절함으로써 코팅막의 특성을 조절할 수 있는 비대칭 바이폴라 펄스 $\mathrm{DC}$ 스퍼터법에 주목하였다. 특히 바이폴라 펄스 $\mathrm{DC}$ 마그네트론 스퍼터법은 기 존의 $\mathrm{DC}$ 스퍼터법에 비해 펄스 전원을 사용하기 때문에 $(+)$ 전압이 인가되는 시간의 존재로 인하여 아크발생이 근본적으로 억제된다. 따라서 미세 아 크로 인해 발생하는 시편의 결함을 방지할 수 있고 플라즈마에 안정성이 높아진다. 또한 펄스 $\mathrm{DC}$ 스 퍼터법은 $\mathrm{DC}$ 스퍼터법에 비해 높은 이온 플럭스와 넓은 이온 에너지 분포를 갖는다고 보고되고 있기 
Table 1. Conditions for deposition of TiAIN coatings by continuous DC and pulsed DC sputtering

\begin{tabular}{|c|c|c|c|c|}
\hline Conditions & 1 & 2 & 3 & 4 \\
\hline Generator (type) & DC & Pulsed DC & Pulsed DC & Pulsed DC \\
\hline Power (W) & 500 & 500 & 500 & 500 \\
\hline Pulse frequency (kHz) & - & 5 & 25 & 50 \\
\hline Duty cycle (\%) & - & 95 & 75 & 50 \\
\hline Substrate bias voltage (V) & DC-100 & DC-100 & DC-100 & DC-100 \\
\hline
\end{tabular}

때문에 높은 이온 에너지를 갖는 이온 플럭스의 증 가는 코팅막의 조성, 조직계수, 미세구조와 물성 등 에 커다란 영향을 미칠 것으로 사료된다 ${ }^{10)}$. 현재까 지 주로 $\mathrm{TiN}$ 보다 우수한 내산화성과 높은 경도를 얻기 위해 다양한 PVD법을 이용한 TiAlN 코팅막 제작에 관한 연구는 많이 발표되었으나 비대칭 바 이폴라 펄스 $\mathrm{DC}$ 스퍼터법을 이용하여 나노결정질 TiAlN 코팅막을 제작했다는 연구는 거의 보고된 바 없다. 특히 듀티 싸이클과 펄스 주파수와 같은 펄 스 플라즈마 공정변수가 TiAIN 코팅막의 평균 결 정립 크기와 표면 및 단면 미세구조의 치밀화에 미 치는 영향을 정량적으로 분석 및 고찰한 연구결과 는 보고된 바 없다 ${ }^{11-12)}$.

따라서 본 연구에서는 TiAlN 코팅막 제작 시 펄 스 플라즈마의 사용, 듀티 싸이클과 펄스 주파수와 같은 펄스 플라즈마 공정 변수가 코팅막의 물성에 미치는 영향을 조사하기 위해 종래의 연속적인 DC 스퍼터와 비대칭 바이폴라 펄스 $\mathrm{DC}$ 스퍼터를 이용 하여 TiAIN 코팅막을 각각 제작하였다. 특히 펄스 플라즈마 변수가 TiAIN 코팅막의 나노결정립 크기, 2 차원 표면 및 단면관찰과 3 차원 표면 거칠기와 같 은 미세구조적 변화에 미치는 영향에 주목하여 고 찰하였다. 또한 우선 배향성, 잔류응력, 나노인덴테 이션 경도와 같은 기계물리학적 특성에 미치는 영 향도 고찰하였다.

\section{2. 실험방법}

본 실험에서는 $\operatorname{Si}(100)$ 기판을 사용하였고, 기판 표면의 불순물을 제거하기 위하여 초음파 세척기를 이용하여 아세톤과 에틸 알코올에서 각각 10 분간 세척을 실시한 후 건조하였다. 본 실험에서 사용한 코팅장비는 비대칭 펄스 $\mathrm{DC}$ 반응성 마그네트론 스 퍼터 장치로 출발원료로는 직경 $3 "$, 두께 $1 / 4 "$, 순 도 $99.995 \%$ 의 TiAl 타겟을 사용하였다. TiAlN 코 팅막의 증착을 위해 초고순도의 $\mathrm{N}_{2}$ 와 $\mathrm{Ar}$ 가스를 사 용하였고 $\mathrm{Ar}$ 과 $\mathrm{N}_{2}$ 가스의 분압조절은 $\mathrm{MFC}$ (Mass Flow Controller)를 이용하여 조절하였다. 증착 시 기판과 타겟간 거리는 $60 \mathrm{~mm}$ 로 유지하고, 균일한
증착을 위해 기판을 약 $10 \mathrm{rpm}$ 의 속도로 회전시켰 다. TiAlN 코팅막은 $\mathrm{Ar}$ 과 $\mathrm{N}_{2}$ 를 적절히 혼합한 분 위기에서 증착하였다. 챔버의 초기압력은 로터리 펌 프와 터보분자펌프를 사용하여 약 $4.0 \times 10^{-4} \mathrm{~Pa}$ 까 지 배기시켰으며 진공도의 측정은 이온 게이지와 바라트론게이지를 이용하였다. 증착 전에 타겟과 기 판을 세척하기 위해 $\mathrm{Ar}$ 플라즈마를 발생시켜 처리 하였다. 코팅막의 물성 비교 및 분석을 위해 종래 의 $\mathrm{DC}$ 전원과 펄스 $\mathrm{DC}$ 전원을 이용하여 $\mathrm{TiAlN}$ 코 팅막을 제작하였으며 표 1 에서는 연속적인 $\mathrm{DC}$ 스 퍼터링과 펄스 $\mathrm{DC}$ 스퍼터링의 성막조건을 나타내 었으며, 이는 펄스 $\mathrm{DC}$ 스퍼터링의 듀티 사이클의 감소 및 펄스 프리퀀시를 증가 시키며 진행하였음 을 알 수 있다. 또한 얻어진 나노결정질 TiAIN 코 팅막의 결정상분석, 집합조직계수, 우선배향성 및 반가폭 등의 분석을 위해 PAN analytical사의 X-ray Diffractometer (XRD)를 사용하였고 3차원적 몰폴 러지와 표면 거칠기 측정을 위해 Thermo-Microscope 사의 Auto Probe Atomic Force Microscopy (AFM)을 이용하였다. 또한 코팅막의 나노 경도 측정은 MTS System사의 정밀경도시험기인 나노인덴테이터를 이 용하였다. 경도는 Berkovich 다이아몬드 압자를 이 용하여 16 번의 실험을 통한 평균값으로 구하였다. 나노인덴터 측정 간격은 이미 실행된 경도 측정 팁 에 영향을 받지 않기 위해 $10 \mu \mathrm{m}$ 이상을 유지하였 다. 또한 모재에 영향을 끼치지 않는 범위에서 경 도를 측정하기 위해 압입 깊이는 코팅막의 두께의 $10 \%$ 정도로 고정하였다.

\section{3. 결과 및 고찰}

\section{1 결정립 크기}

코팅막의 평균 결정립 크기는 거의 모든 분야의 응용분야에서 물성을 좌우하는 매우 중요한 요소로 결정립 크기의 감소는 잔류응력과 경도를 증가시켜 코팅막의 접착력과 내마모성을 향상시킨다. 따라서 결정립 크기의 정확한 측정은 코팅막의 응용 최적 화에 매우 중요한 요소이다. 결정립 크기 측정을 위 해 투과전자 현미경을 이용하면 일반적으로 시편제 


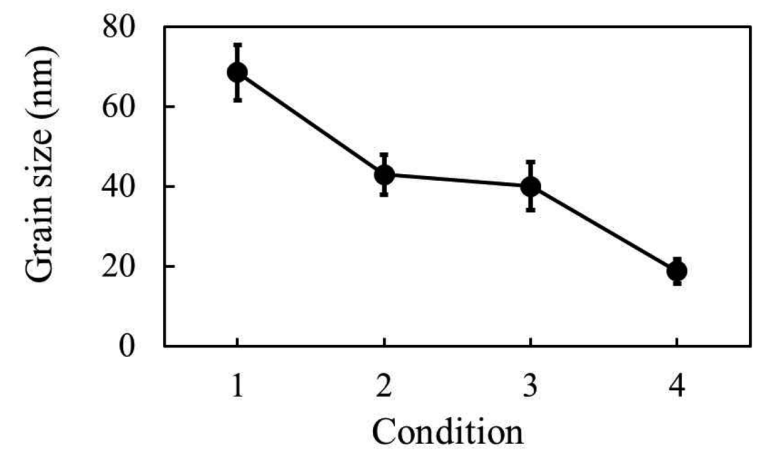

Fig. 1. The grain sizes of TiAIN films deposited by DC and Pulsed DC sputtering.

작과 관찰에 많은 시간과 비용이 요구된다. 따라서 이를 개선하고 단순화시킨 새로운 접근방법은 $\mathrm{X}$ 선 회절분석을 이용한 결정립 크기의 측정이다 ${ }^{13)}$. 그 림 1 에 $\mathrm{DC}$ 스퍼터법 및 비대칭 바이폴라 펄스 $\mathrm{DC}$ 스퍼터법으로 제작한 TiAlN 코팅막의 결정립 크기 변화를 나타냈다. 코팅막의 결정립 크기는 $\mathrm{X}$ 선 회 절분석 피크의 반가폭 크기로도 계산이 가능한데 일반적으로 반가폭 크기가 클수록 결정립 크기는 작아진다. 본 실험에서 결정립 크기는 Scherrer법을 이용하여 계산하였고 반가폭이 증가할수록 결정립 크기는 감소하였다 ${ }^{14}$. 그림에서 알 수 있듯이 듀티 싸이클 감소와 펄스 주파수 증가에 따라 TiAlN 코 팅막의 결정립 크기는 $68.5 \mathrm{~nm}$ 부터 $18.7 \mathrm{~nm}$ 까지 거 의 직선적으로 감소함을 알 수 있다. 따라서 TiAlN 코팅막의 미세구조를 제어하는 기술로서 비대칭 바 이폴라 펄스 $\mathrm{DC}$ 스퍼터법과 듀티 싸이클 및 펄스 주파수는 매우 중요한 공정변수임을 알 수 있다.

이러한 TiAlN 코팅막의 결정립 크기의 나노화 원 인으로는 이온 에너지, 이온 플럭스, 잔류 불순물 및 결정학적 집합조직과 같은 복합적인 요소들의 영향을 들 수 있다 ${ }^{15}$. 본 연구에서는 성막 중 음전 하를 띤 스퍼터 원자의 포격이 코팅막 안에 손상을 입혀 다수의 결함이 막 안에 형성되었다고 사료된 다. 이러한 결함의 밀도는 고에너지의 스퍼터 원자 때문에 증가하게 되며 성막 중 기판 위에 반복적인 핵생성을 유발시킨다. 불순물들은 입계에 석출하게 되고 Zener drag로 인해 입성장이 제한되기 때문에 이는 나노결정질 TiAlN 코팅막의 형성 및 유지에 매우 유리하다 ${ }^{16}$.

\section{2 미세구조}

$\mathrm{DC}$ 및 펄스 $\mathrm{DC}$ 스퍼터법으로 제작된 $\mathrm{TiAlN}$ 코 팅막의 미세구조를 FE-SEM을 이용하여 관찰하였 고 그 표면 사진을 그림 2에 나타내었다. $\mathrm{DC}$ 스퍼 터로 제작된 TiAIN 코팅막의 표면 사진에서는 평

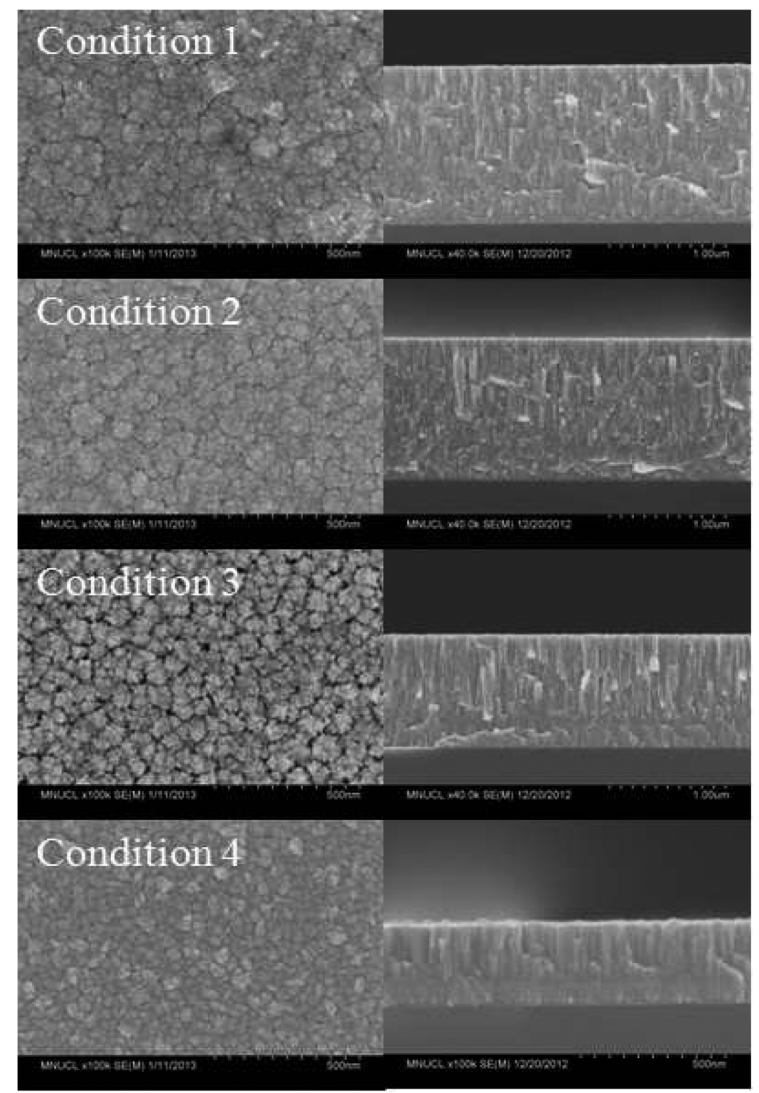

Fig. 2. Top surface and cross-sectional FE-SEM images of TiAIN films deposited by DC and Pulsed DC sputtering.

균크기 $60 \sim 80 \mathrm{~nm}$ 이상의 주상구조의 다공성 결정 립이, 펄스 $\mathrm{DC}$ 스퍼터로 제작된 TiAIN 코팅막의 표면에서는 평균크기 $10 \sim 20 \mathrm{~nm}$ 이하의 치밀한 결 정립으로 미세화되어감을 관찰할 수 있다. 일반적 으로 펄스 플라즈마의 생성에 따른 이온전류의 상 승은 핵생성 밀도를 증가시켜 결과적으로 매우 작 은 결정립으로 구성된 치밀한 미세구조의 코팅막이 형성된다. 또한 본 연구에서는 성막 중 기판에 $\mathrm{DC}$ $-100 \mathrm{~V}$ 의 바이어스 전압을 인가했기 때문에 $60 \sim$ $80 \mathrm{eV}$ 범위의 이온 에너지 분포를 갖는 다수의 이온 들이 기판을 향해 이온 포격된 것으로 사료된다 ${ }^{17)}$. 따라서 이러한 이온 포격효과와 성막속도의 감소 (condition 4의 경우 약 $0.1 \mathrm{~nm} / \mathrm{s}$ 로 condition 1 에 비 해 $1 / 3$ ) 라는 복합적인 요소에 의해 코팅막의 미세 구조는 미세화 및 치밀화되었다고 사료된다.

\section{3 우선 배향성 및 잔류응력}

$\mathrm{DC}$ 스퍼터법 및 비대칭 바이폴라 펄스 스퍼터법 으로 제작한 TiAlN 코팅막의 X선 회절분석 결과를 그림 3에 나타내었다. 모든 코팅막에서 (111)면과 (200)면의 피크가 관찰되었으며, 코팅막 제작방법 및 공정변수 차이로 인한 $\mathrm{X}$ 선 회절금속 결과는 눈 


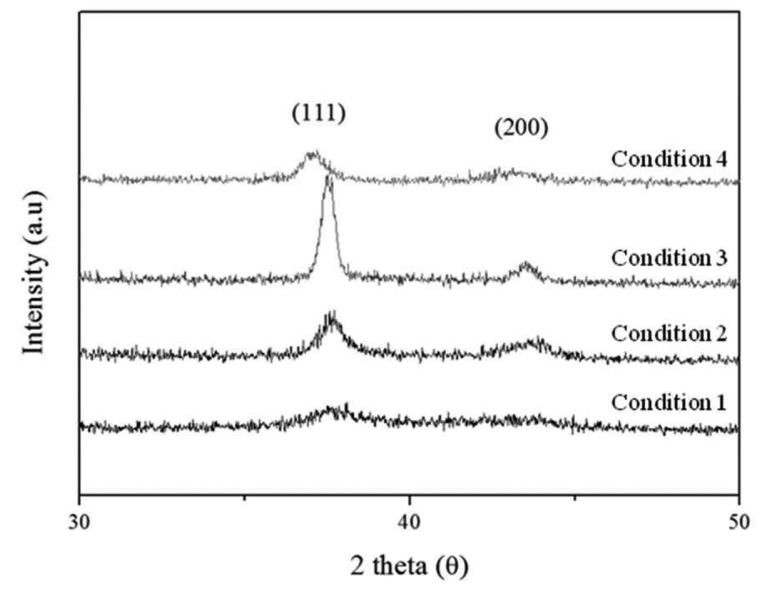

Fig. 3. XRD data of TiAIN films deposited using DC and Pulsed DC sputtering.

에 띄는 변화가 우선 배향성에서는 발견되지 않았 다. 그러나 비대칭 바이폴라 펄스 스퍼터법의 사용 과 코팅 중 듀티 싸이클의 감소 및 펄스 주파수 증 가에 따라 $\mathrm{X}$ 선 회절분석 피크의 반가폭은 연속적 으로 감소함을 알 수 있다. 코팅 중 듀티 싸이클 및 펄스 주파수가 TiAlN 코팅막 내에 잔류응력에 미 치는 영향을 알아보기 위해 (111)면과 (200)면의 $2 \theta$ 분석결과를 표 2에 나타내었다. 코팅 중 펄스 플라 즈마 변수에 따라 TiAlN 회절 피크의 포지션 변화 에 미치는 영향을 쉽게 표현하기 위해 JCPDS 카 드(\#37-1140)로부터 구한 TiAlN (111)면과 (200)면 의 표준 $2 \theta$ 값을 함께 표시했다. 펄스 플라즈마 공 정변수에 따라서 (111)면과 (200)면의 측정 20값은 TiAlN JCPDS 카드의 표준 $2 \theta$ 값보다 감소함을 명 확히 알 수 있다. 이러한 $2 \theta$ 값의 저각으로의 이동 은 응력변화에 기인한다고 사료된다.

일반적으로 PVD 프로세스를 이용하여 제작된 코 팅막에는 상당량의 잔류응력이 존재하기 때문에 내 마모성과 경도가 증가하나 반면 접착력은 감소한 다 ${ }^{18)}$. 이러한 PVD 프로세스를 이용하여 제작된 코 팅막에 존재하는 압축응력은 $\mathrm{Ar}^{+}$이온 포격에 의해 생성된 점 결함과 밀접한 관계를 갖는다. 주상구조 를 갖지 않는 치밀한 미세구조를 갖는 코팅막을 제 작하기 위해서는 이온 포격이 요구되며 이러한 이 온 포격효과는 결정립 크기의 미세화 및 부착력 향 상에 커다란 영향을 미친다 ${ }^{19)}$. 실제로 본 실험에서

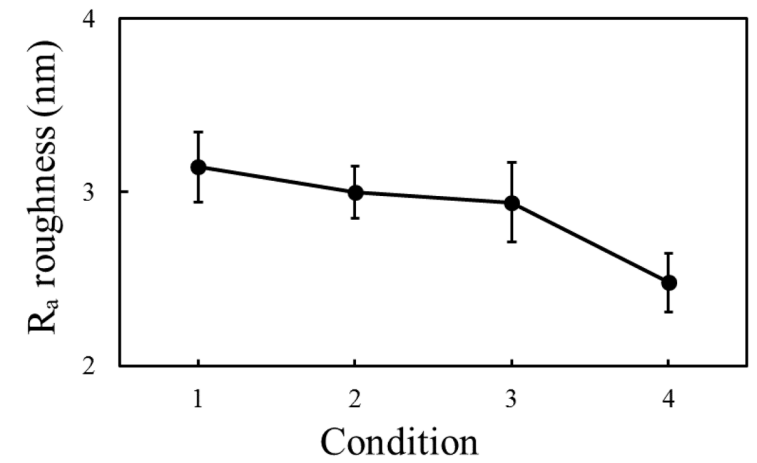

Fig. 4. Average surface (Ra) roughness of TiAIN films deposited using DC and Pulsed DC sputtering.

얻어진 TiAlN 코팅막 내부에는 상당량의 잔류응력 이 존재한다고 사료된다. 그 증거로서 표 2의 X선 회절분석 결과를 면밀히 관찰해보면 $\mathrm{DC}$ 스퍼터법 으로 제작된 TiAlN 코팅막의 $2 \theta$ 값보다 펄스 $\mathrm{DC}$ 스 퍼터법으로 제작된 TiAIN 코팅막이 낮은 $2 \theta$ 값을 갖고 있음을 알 수 있는데 이는 코팅막 내부 압축 응력의 증가를 시사한다 ${ }^{20-22)}$.

\section{4 표면 거칠기}

코팅 중 듀티 싸이클과 펄스 주파수 변화가 TiAlN 코팅막의 표면 거칠기에 미치는 영향을 밝히기 위 해 비접촉식 $\mathrm{AFM}$ 분석을 실시하였고 그 결과를 그림 4에 나타내었다. 코팅 중 듀티 싸이클과 펄스 주파수가 TiAlN 코팅막의 $\mathrm{R}_{\mathrm{a}}$ (Roughness average) 표면 거칠기에 미치는 결과를 비교하면 펄스 스퍼 터법으로 제작한 TiAlN 코팅막의 표면이 종래의 $\mathrm{DC}$ 스퍼터법으로 코팅한 TiAlN 코팅막보다 평탄하 다는 점이다. 예를 들면 연속적인 $\mathrm{DC}$ 스퍼터법으로 제작한 TiAlN 코팅막의 $\mathrm{R}_{\mathrm{a}}$ 표면 거칠기는 $3.1 \mathrm{~nm}$ 인 반면 듀티 싸이클 $50 \%$ 와 펄스 주파수 $50 \mathrm{kHz}$ 를 인 가하여 제작한 TiAlN 코팅막의 $\mathrm{R}_{\mathrm{a}}$ 표면 거칠기는 $2.4 \mathrm{~nm}$ 이다. 펄스 스퍼터법으로 제작된 TiAlN 코팅 막의 매끄러운 표면 몰폴러지는 이온 전류 밀도와 밀접한 관계를 갖는다고 보고된바 있으며, 실제로 펄스 $\mathrm{DC}$ 스퍼터법을 이용하면 $\mathrm{DC}$ 스퍼터법에 비 해 약 $40 \sim 80 \%$ 높은 이온 전류가 얻어진다고 보 고되고 있다 ${ }^{23)}$. 따라서 본 연구에서도 위와 같은 펄 스 플라즈마의 생성에 따른 이온전류의 증가가 매

Table 2. XRD data of TiAIN films for DC and pulsed DC sputtering

\begin{tabular}{|c|c|c|c|c|c|c|c|c|c|c|}
\hline \multirow{2}{*}{ TiAIN } & \multicolumn{10}{|c|}{ Peak position } \\
\hline & \multicolumn{5}{|c|}{ (111) } & \multicolumn{5}{|c|}{ (200) } \\
\hline Duty cycle (\%) & 100 & 95 & 75 & 50 & standard & 100 & 95 & 75 & 50 & standard \\
\hline $2 \theta\left({ }^{\circ}\right)$ & 38.13 & 37.71 & 37.23 & 37.04 & 37.88 & 43.96 & 43.90 & 43.54 & 42.92 & 44.04 \\
\hline
\end{tabular}




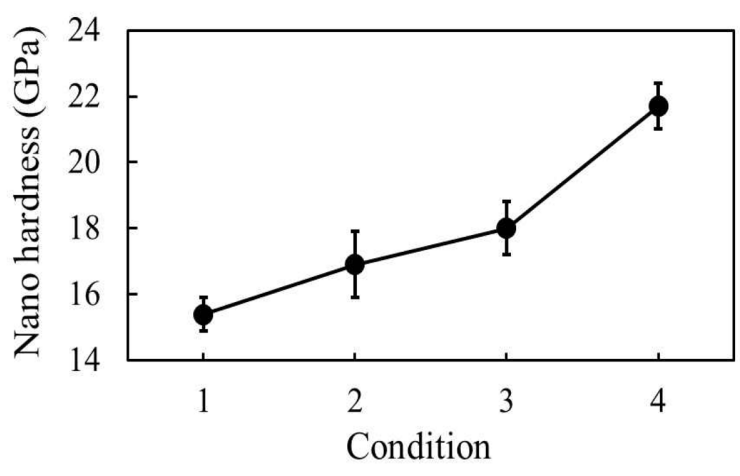

Fig. 5. The nanoindentation hardness of TiAIN films prepared at DC and Pulsed DC sputtering.

끄러운 표면 몰폴러지를 갖는 TiAlN 코팅막의 형 성에 기여했다고 사료된다.

\section{5 나노 경도}

$\mathrm{DC}$ 스퍼터법 및 비대칭 펄스 스퍼터법으로 제작 한 TiAlN 코팅막의 기계적 경도를 나노인덴테이션 장비를 이용하여 측정하였고 이를 그림 5 에 나타내 었다. 나노인덴테이션 기술은 아주 작은 양의 재료 의 기계적 성질을 얻기 위해 가장 간단하고 직접적 인 방법으로 사용된다 ${ }^{24)}$. 본 연구에서 코팅막의 나 노 경도 측정을 위한 입자의 인가하중은 $5 \mathrm{mN}$ 으로 고정했으며, 압입 깊이가 얕을수록 측정된 경도 값 이 증가하는 경향을 보이는 인덴테이션 크기 효과 ${ }^{25)}$ 를 배제하기 위하여 전체 막 두께의 $1 / 10$ 지점으로 평균화하였다. 본 연구 결과에서 종래의 $\mathrm{DC}$ 스퍼 터법 보다 비대칭 펄스 $\mathrm{DC}$ 스퍼터법으로 제작한 TiAlN 코팅막의 나노 경도값이 높음을 알 수 있다. 이러한 TiAlN 코팅막의 나노 경도는 듀티 싸이클 의 감소와 펄스 주파수의 증가에 따라 증가함을 알 수 있는데 예를 들면 듀티 싸이클 $50 \%$ 와 펄스 주 파수 $50 \mathrm{kHz}$ 에서 제작된 TiAlN 코팅막의 나노 경 도값은 약 $22 \mathrm{GPa}$ 로 $\mathrm{DC}$ 스퍼터법으로 제작한 TiAlN 코팅막의 나노 경도값 $15 \mathrm{GPa}$ 보다 약 1.5 배 증가함을 알 수 있다. 이러한 펄스 $\mathrm{DC}$ 스퍼터법으 로 제작된 TiAlN 코팅막의 나노 경도의 상승원인 은 DC 스퍼터법으로 제작한 TiAlN 코팅막에 비해 높은 이온화를 가지며 고밀도 플라즈마의 생성으로 인한 결정립 크기의 감소에 따른 미세구조의 치밀 화, 기판바이어스 전압인가에 따른 높은 이온포격 효과 및 압축응력의 상승에 주로 기인한다고 사료 된다.

\section{4. 결 론}

본 연구에서는 $\mathrm{DC}$ 스퍼터법과 비대칭 바이폴라 펄스 $\mathrm{DC}$ 스퍼터법을 이용하여 나노결정질 TiAlN 코팅막을 제작하였으며, 타겟에 인가되는 펄스 플 라즈마 전원의 사용유무와 듀티 싸이클과 펄스 주 파수가 TiAlN 코팅막의 몰폴러지와 같은 미세구조 적 변화와 나노 경도와 같은 기계적 특성 변화에 미치는 영향에 대해 조사하였다. 듀티 싸이클 $50 \%$ 와 펄스 주파수 $50 \mathrm{kHz}$ 를 인가하여 제작된 TiAlN 코팅막의 평균 결정립 크기와 $\mathrm{R}_{\mathrm{a}}$ 표면 거칠기는 각 각 $18.7 \mathrm{~nm}$ 와 $2.4 \mathrm{~nm}$ 로 가장 조밀하고 평탄한 몰폴 러지를 갖는 코팅막을 제작할 수 있었다. X선 회절 분석 결과 주로 (111)면의 집합조직발달이 관찰되 었으나 (111)면과 (200)면 모두 20값은 감소하여 TiAlN 코팅막 내 압축응력이 증가함을 나타냈다. 또한 비대칭 바이폴라 펄스 스퍼터법으로 제작한 TiAlN 코팅막의 나노 경도는 약 $22 \mathrm{GPa}$ 로 $\mathrm{DC}$ 스 퍼터법으로 제작한 코팅막에 비해 약 1.5 배 증가하 였다. 따라서 듀티 싸이클과 펄스 주파수와 같은 펄 스 플라즈마 변수를 조절하여 종래의 $\mathrm{DC}$ 스퍼터법 보다 치밀하고 평탄한 미세구조, 우선 배향성과 기 계적 특성을 갖는 나노결정질 TiAlN 코팅막을 제 작할 수 있었다.

\section{Acknowledgment}

본 과제(결과물)는 교육부의 재원으로 지원을 받 아 수행된 산학협력 선도대학(LINC) 육성사업의 연 구결과입니다.

\section{References}

1. S. Y. Yoon, Y. B. Lee, K.H. Kim J. Kor. Inst. Surf. Eng.. 35 (2002) 193.

2. M. S. Kim, J. H. Kho, S. H. Kim, J. Kor. Inst. Surf. Eng., 43 (2010) 278.

3. S. Hogmark, S. Jacobson, M. Larsson, Wear, 246 (2000) 20.

4. L. Persano, A. Camposeo, P. Del Carro, E. Mele, R. Cingolani, D. Pisignano, Optics Express, 14 (2006) 1951

5. J. L. Gomez, O. Tigli, J. Mater. Sci., 48 (2013) 612.

6. A. Moustaghfir, E. Tomasella, A. Rivaton, B. Mailhot, M. Jacquet, J. L. Gardette, Surf. Coat. Tech., 180-181 (2004) 642.

7. J. Baumann, M. Markert, T. Werner, A. Ehilich, M. Rennau, Ch. Kaufmann, Micro Electron. Eng., 
37 (1997) 229.

8. D. H. Yu, C. Y. Wang, X. L. Cheng, F. L. Zhang, Appl. Surf. Sci., 255 (2008) 1865.

9. S. Y. Tan, X. H. Zhang, X. J. Wu, F. Fang, J. Q. Jiang, Thin Solid Films, 519 (2011) 2116.

10. J. Sellers, Surf. Coat. Tech., 98 (1998) 1245.

11. G. S. Kim, B. S. Kim, S. Y. Lee, J. Kor. Inst. Surf. Eng., 38 (2005) 207.

12. H. C. Barshilia, K.S. Rajam, Surf. Coat. Tech., 201 (2006) 1827.

13. K. Bobzin, E. Lugscheider, M. Maes, P. Immich, S. Bolz, Thin Solid Films, 515 (2007) 3681

14. S. Y. Chun, J. W. Baek, J. Kor. Inst. Surf. Eng.. 47 (2014) 100.

15. I. Petrov, P. B. Barna, L. Hultman, J. E. Greene, J. Vac. Sci. Tech. A, 21 (2003) 774.

16. N. Maazi, N. Rouag, J. Cryst, Growth, 243 (2002) 361.

17. H. C. Barshilia, K. Yogesh, K. S. Rajam, Vacuum,
83 (2009) 427.

18. M. Ahlgren, H. Blomqvist, Surf. Coat. Tech., 200 (2005) 157.

19. I. Petrov, L. Hultman, U. Helmersson, S. A. Barnett, J. E. Sundgern, J. E. Green, Thin Solid Films, 169 (1989) 299.

20. C. P. Constable, D. B. Lewis, J. Yarwood, W. D. Münz., Surf. Coat. Tech., 184 (2004) 291-297.

21. D. W. Hoffmann, Thin Solid Films 107 (1983) 353-358.

22. A. Pan, J. E. Greene, Thin Solid Films 78 (1981) 25-34.

23. L. Hultman, U. Helmersson, S. A. Barnett, J. E. Sundgren, J. E. Greene, J. Appl. Phys., 61 (1987) 552.

24. J. M. Lee, C. J. Lee, K. H. Lee, B. M. Kim, Trans. Nonferrous Met. Soc. China, 22 (2012) 585.

25. S. Kim, D. M. Kim, S. Kang, H. J. Kim, J. Kor. Ceram. Soc., 46 (2009) 116. 